\title{
Randy Reichardt: Blog Master and Engineering Librarian Extraordinaire
}

Sandy Campbell

University of Alberta

When Randy Reichardt created the STLQ blog - The SciTech Library Question occasional postings of issues and concerns of interest (but not limited to) engineering and scitech librarians (http://stlq.info/) in 2003, he wanted a forum where Science and Technology Librarians could carry on conversations. STLQ now has several hundred subscribers and readers and has been cited as an exemplary model by both librarians and researchers in other fields. Randy has spoken and published nationally and internationally on blogs in libraries and coached many librarians in the development of their own blog applications.

While Randy's work has helped incorporate blog technology into mainstream library practice, his work with educating students in the use of blogs has also had considerable impact. As an Engineering Librarian at the University of Alberta, Randy works with a number of senior level design courses in Chemical, Materials and Mechanical Engineering, offering students library instruction and information consultation. In 2004, responding to a request from a student group for help with the management of their project, Randy helped them organize a blog for communication and project organization. Since that time, Randy has taught hundreds of students to use blogs as their project management tool. Many groups add Randy as a subscriber to their blogs, so that their design team has their very own librarian as a member!

When he's not making sure that Engineering students graduate from the University of Alberta with a full toolkit of information skills, Randy can be found volunteering with Big Brother/Big Sisters and playing top-notch guitar with several local Edmonton groups including Hardy Drew and the Nancy Boys (http://www.myspace.com/hdnb). 